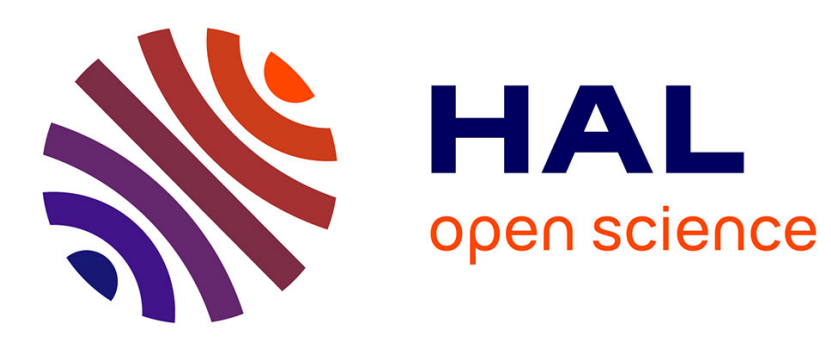

\title{
Fuzzy Controlled Parallel PSO to Solving Large Practical Economic Dispatch
}

Belkacem Mahdad, Kamel Srairi, Tarek Bouktir, Mohamed Benbouzid

\section{To cite this version:}

Belkacem Mahdad, Kamel Srairi, Tarek Bouktir, Mohamed Benbouzid. Fuzzy Controlled Parallel PSO to Solving Large Practical Economic Dispatch. IEEE IECON 2010, Nov 2010, Phoenix, United States. pp.2695-2701, 10.1109/IECON.2010.5675112 . hal-00564733

\section{HAL Id: hal-00564733 https://hal.science/hal-00564733}

Submitted on 9 Feb 2011

HAL is a multi-disciplinary open access archive for the deposit and dissemination of scientific research documents, whether they are published or not. The documents may come from teaching and research institutions in France or abroad, or from public or private research centers.
L'archive ouverte pluridisciplinaire HAL, est destinée au dépôt et à la diffusion de documents scientifiques de niveau recherche, publiés ou non, émanant des établissements d'enseignement et de recherche français ou étrangers, des laboratoires publics ou privés. 


\title{
Fuzzy Controlled Parallel PSO to Solving Large Practical Economic Dispatch
}

\author{
Belkacem Mahdad, Member, IEEE, K. Srairi, T. Bouktir, M. EL. Benbouzid, Senior Member, IEEE
}

\begin{abstract}
This paper presents a fuzzy controlled parallel particle swarm optimization approach based decomposed network (FCP-PSO) to solving the large economic power dispatch with non-smooth cost fuel functions. The proposed approach combines practical experience extracted from global database formulated in fuzzy rules, the adaptive PSO executed in parallel based in decomposed network procedure as a local search to enhance the search space around the global search. The robustness of the proposed modified PSO tested on $\mathbf{4 0}$ generating units with prohibited zones and compared with recent hybrid global optimization methods. The results show that the proposed approach can converge to the near solution and obtain a competitive solution at critical situation and with a reasonable time.
\end{abstract}

Key Words-Parallel Genetic Algorithm, Decomposed Network, PSO, economic dispatch, Fuzzy logic, Fuzzy Controlled, Planning and control.

\section{INTRODUCTION}

$\mathrm{T}$ The economic dispatch problem (EDP) is one of the important problems in modern power system operation and planning. In its most general formulation, the economic power dispatch (EPD) is a nonlinear, nonconvex, large-scale, static optimization problem with both continuous and discrete control variables. The global optimization techniques known as genetic algorithms (GA), simulated annealing (SA), tabu search (TS), and evolutionary programming (EP), which are the forms of probabilistic heuristic algorithm have been successfully used to overcome the non-convexity problems of the constrained ED [1].

The literature on the application of the global optimization in the OPF problem is vast and [1] represents the major contributions in this area. In [2] authors presented an improved coordinated aggregation-based particle swarm optimization (ICA-PSO) algorithm for solving the optimal economic dispatch, the obtained results are compared to many large recent heuristic optimization techniques (HOT) given in the literature. Authors in [3] present a new fuzzy hybrid particle swarm optimization algorithm for non-linear, nonsmooth and non-convex economic dispatch problem. In [4] authors present a novel string structure for solving the economic dispatch through genetic algorithm (GA). To accelerate the search process authors in [5] proposed a

Belkacem Mahdad is with the Department of Electrical Engineering, University of Biskra Algeria (e-mail: bemahdad@yahoo.fr). multiple tabu search algorithm (MTS) to solve the dynamic economic dispatch (ED) problem with generator constraints, simulation results prove that this approach is able to reduce the computational time compared to the conventional approaches. PSO algorithm is one of the modern heuristic evolutionary techniques widely used in recent years and suitable to solve large-scale nonconvex optimization problem.

PSO has parallel search techniques. Due to its high potential for global optimization, PSO has received great attention in solving optimal power flow (OPF) problems with consideration of discontinuous fuel cost functions. The main advantages of the PSO algorithm are: simple concept, easy implementation, and computational efficiency. Although the PSO-based approaches have several disadvantages, it may get trapped in a local minimum when handling heavily constrained problems due to the limited local/global searching capabilities. Many hybrid methods have been proposed to enhance the performance of the standard PSO algorithm [7$15]$.

In general to overcome the drawbacks of the conventional methods related to the form of the cost function, and to reduce the computational time related to the large space search required by many global optimization methods, authors in [616-17] proposed an efficient decomposed GA for the solution of large-scale OPF with consideration of shunt FACTS devices under severe loading conditions. This paper presents an efficient combined approach based fuzzy rules and PSO based decomposed network to enhance the global solution of large economic dispatch with consideration of practical generator constraints.

\section{ACTIVE POWER DisPatch WITH DiscontinUous FUEL COST FUNCTIONS}

The main role for economic dispatch is to minimize the total generation cost of the power system but still satisfying specified constraints (generators constraints and security constraints).

\section{A. ED with smooth cost function}

For optimal active power dispatch, the simple objective function $f$ is the total generation cost as expressed follows:

$$
\operatorname{Min} f_{T}=\sum_{i=1}^{N g}\left(a_{i}+b_{i} P_{g i}+c_{i} P_{g i}^{2}\right)
$$

where;

$f_{T} \quad:$ total generation cost; 
$P_{g i} \quad$ : active power generation at unit $\mathrm{i}$;

$a_{i}, b_{i}, c_{i} \quad:$ cost coefficients of the $i^{t h}$ generator;

$N_{g} \quad:$ is the number of generators.

\section{B. ED with non-smooth cost function with valve-point loading effects}

The ED with valve-point effect can be represented as a nonsmooth optimization problem having complex and nonconvex features with heavy equality and inequality constraints. The valve-point loading is taken in consideration by adding a sine component to the cost of the generating units. Typically, the fuel cost function of the generating units with valve-point loadings is represented as follows:

$$
f_{T}=\sum_{i=1}^{N_{g}}\left(a_{i}+b_{i} P_{g i}+c_{i} P_{g i}^{2}\right)+\left|d_{i} \sin \left(e_{i}\left(P_{i}^{\min }-P_{i}\right)\right)\right|
$$

$d_{i}$ and $e_{i}$ are the cost coefficients of the unit with valve-point effects.The input-output performance curve for a typical thermal unit can be represented as shown in Fig 1.

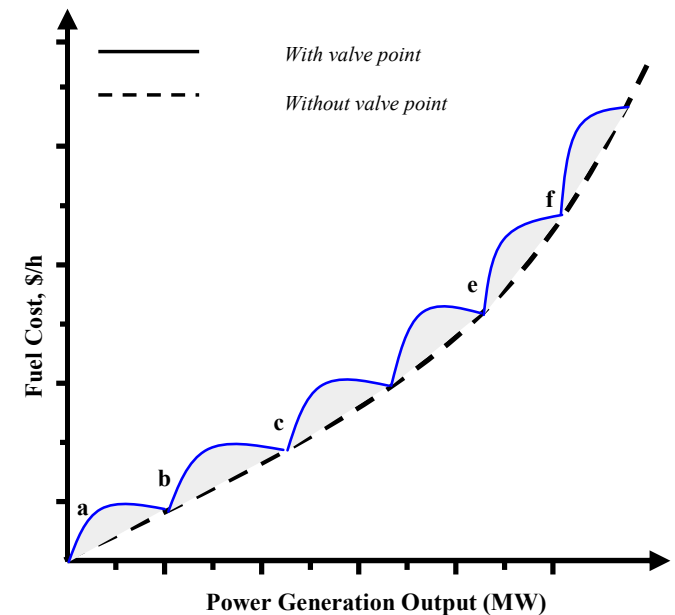

Fig 1 Input-Output curve under valve-point loading

\section{The equality constraints:}

For active power balance, the total generated power should be the same as the total demand plus the total power loss.

$$
\sum_{i=1}^{N G} P_{g i}-P_{D}-P_{l o s s}=0
$$

where $P_{D}$ is the total active power demand, $P_{\text {loss }}$ represent the transmission losses.

\section{The inequality constraints:}

Power output of generator should $b$ within its minimum and maximum limits. The inequality constraint for each generator expressed as follows:

$$
P_{g i}^{\min } \leq P_{g i} \leq P_{g i}^{\max }
$$

where $P_{g i}^{\min }$ and $P_{g i}^{\max }$ are the minimum and maximum active power generation limits of generator $i$, respectively.

\section{FUZZY RULES CONTROLLED PSO}

\section{A. Overview of PSO Method}

Particle swarm optimization (PSO), first introduced by Kennedy and Eberhart in 1995 [11] is one of the modern heuristic algorithms. It was developed through simulation of a simplified social system, and has been found to be robust in solving complex optimization system. The mathematical model for PSO is as follows.

$$
\begin{aligned}
V_{i}^{k+1}=\omega V_{i}^{k} & +c_{1} \text { rand } \times\left(\text { Pbest }_{i}^{k}-X_{i}^{k}\right) \\
& +c_{2} \text { Rand } \times\left(\text { Gbest }^{k}-X_{i}^{k}\right)
\end{aligned}
$$

where;

$V_{i}^{k} \quad$ : velocity of particle $\mathrm{i}$ at iteration $\mathrm{k}$;

$\omega \quad$ : inertia weight factor;

$c_{1}, c_{2}$ : acceleration constant;

$X_{i}^{k} \quad$ : position of particle $\mathrm{i}$ at iteration $\mathrm{k}$;

Pbest $_{i}^{k} \quad$ : best position of particle i until iteration $\mathrm{k}$;

Gbest $^{k} \quad$ : best position of group until iteration k;

Once the velocity has been determined it is simple to move the particle to its next location, and a new coordinate $X_{i}^{k+1}$ is computed for each of the $\mathrm{N}$ dimensions according to the following equation:

$$
X_{i}^{k+1}=X_{i}^{k}+V_{i}^{k+1}
$$

\section{B. Hybrid-Modified PSO based ED}

For better results and to get faster convergence, conventional PSO methods have been modified. In recent years various combined techniques have been studied to achieve this objective, these include [2]:

- $\quad$ Simulated annealing-PSO (SA-PSO).

- Quantum-Inspired version of the PSO using the harmonic oscillator (HQ-PSO).

- Particle swarm optimization with chaotic and Gaussian approaches (PSO-CG).

- Self-organizing hierarchical particle swarm optimization (QOH-PSO).

- $\quad$ Modified particle swarm optimization (MPSO).

- Hybrid particle swarm optimization with sequential quadratic programming (PSO-SQP).

- Improved coordinated aggregation-based PSO (ICAPSO). 


\section{Why Fuzzy Logic Method?}

The use of fuzzy logic has received increased attention in recent years because of it's usefulness in reducing the need for complex mathematical models in problem solving. Fuzzy logic employs linguistic terms, which deal with the causal relationship between input and output variables. For this reason, the approach makes it easier to manipulate and solve problems.

This approach proposes a flexible PSO Algorithm based on fuzzy logic rules with the ability to adjust dynamically three parameters:

- Inertia weight, 'w'

- The two learning factors ' $\mathrm{c} 1$ ' and 'c2'.

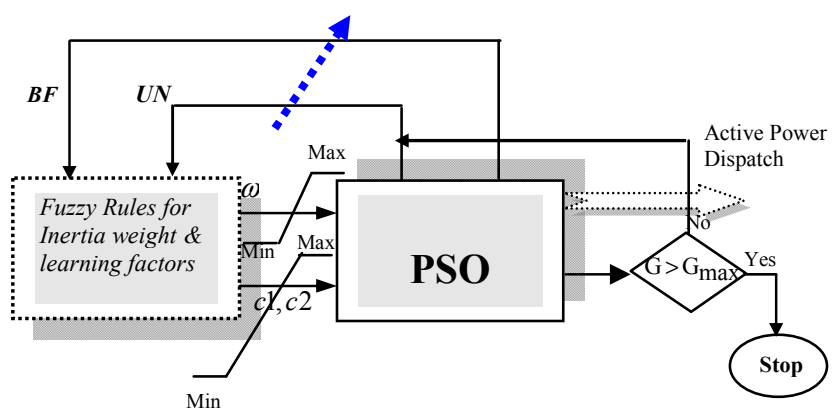

Fig. 2 Block diagram of the PSO parameters adjustment.

Fig. 2 presents the proposed block diagram of a fuzzy controlled PSO.

Inertia weight (w) and the two learning factors are considered critical for PSO convergence. A suitable value for weighing factor and learning factors provides balance between global and local exploration abilities and consequently results in a reduction of the number of iterations required to locate the optimum solution. Experimental results based in application of PSO to many practical networks at normal and abnormal conditions with load incrementation indicated, that it is better to adjust dynamically the value of the three parameters (w, c1 and $\mathrm{c} 2$ ) to assure convergence to the near global solution. $c_{1}$ and $c_{2}$ are scaling factors that determine the relative 'pull' of pbest and gbest. $c_{1}$ is a factor determining how much the particle is influenced by the memory of his best location, and $c_{2}$ is a factor determining how much the particle is influenced by the rest of the swarm. So if $\mathrm{c} 1>\mathrm{c} 2$, the particle has the tendency to converge to the best position found by itself Pbesti rather than the best position found by the population Gbest .

The proposed approach employs in the first stage practical rules interpreted in fuzzy logic rules to adjust dynamically the three parameters (inertia weight, and the two learning factors) during execution of the PSO algorithm, in the second stage parallel execution of PSO based decomposed network [6-16].

\section{1) Membership Function Design}

The membership function adopted by engineer differences from person to person and depends in problem difficulty therefore they are rarely optimal in terms of reproduced desired output.

\section{2) Inputs and Outputs of Fuzzy Controller.}

The main role of this controller is to improve the global searching capability and to increase the probability of escaping from a local minimum. A mechanism search based fuzzy rules designed to adjust dynamically the PSO parameters. The inputs of the proposed search mechanism based fuzzy controller are: changes of the best fitness which reflect the diversity in the cost generation, and the number of generation for unchanged fitness, the output is the variation in weighting factor and the variation in learning (acceleration) factors. The membership functions of inputs and outputs variables are shown in Fig. 3. Sample fuzzy rules for weight factor and learning factors are presented in Fig. 4.

In this study, the upper and lower value for weighting factor and for the two learning factors, respectively are changed based in membership functions for each variable from 1.3 to 0.3 and from 1 to 2 . The final values of inertia weight ' $w$ ' and for the learning factors are calculated based on the fuzzy mechanism search presented in Fig. 2.

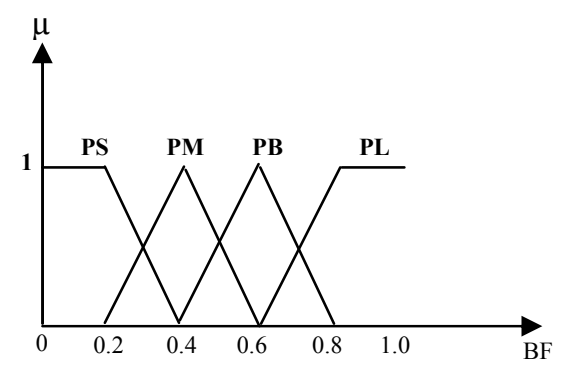

(a)
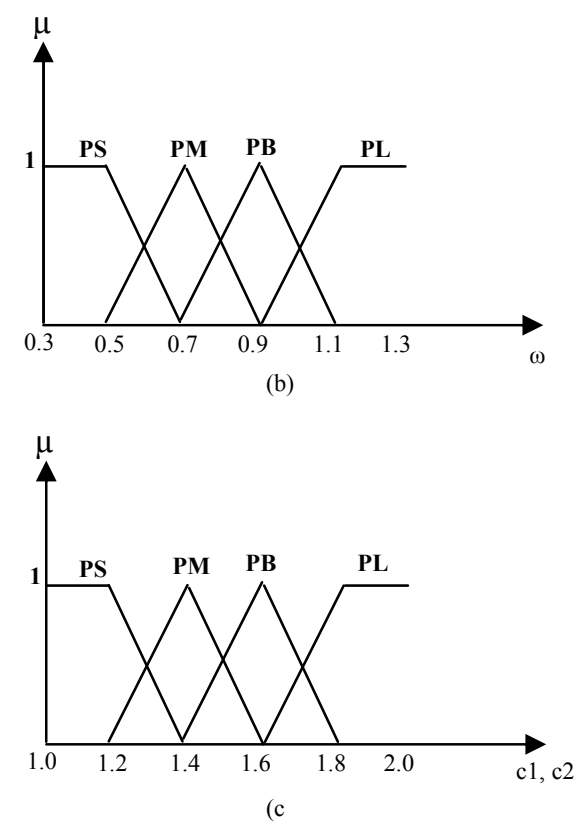

Fig 3 Membership functions: (a) best fitness Bf, (b) weighting factor $\omega$, (c) learning factors $\mathrm{c} 1, \mathrm{c} 2$. 


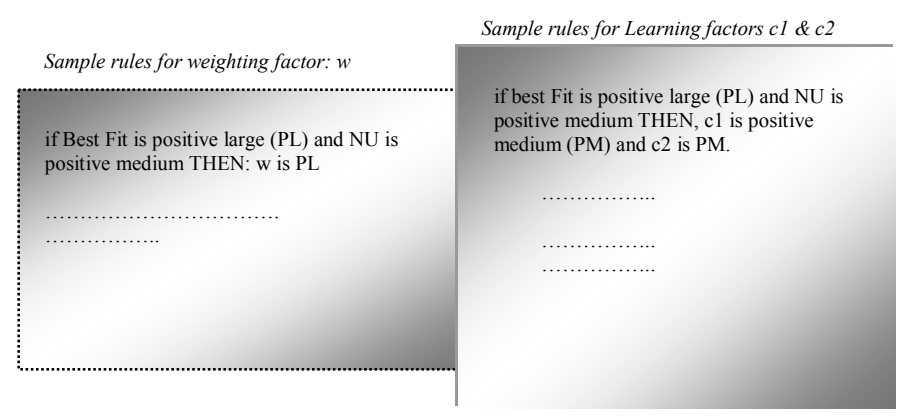

Fig 4 Sample fuzzy rules for PSO parameters tuning.

\section{Calculation Steps of the Proposed Method}

The modified PSO algorithm formulated as follows:

Step1: the particles are randomly generated between the maximum and minimum operating limits as follows:

$$
P g_{i j}^{0}=P g_{j}^{\min }+r_{i j} \cdot\left(P g_{j}^{\max }-P g_{j}^{\min }\right)
$$

Where $r_{i j}$ is a uniformly distributed random number between [0 1]. The minimum and maximum power outputs should be adjusted using (4).

Step2: The particle velocities are generated randomly. Step3: Objective function values of the particles are evaluated. These values are set the best value of the particles.

The structure of Evaluation function fit or fitness function is important to speed up the convergence of the iteration procedure. The evaluation function [5] is adopted as (10). It is the reciprocal of the generation cost function $F_{\cos t}\left(P g_{i}\right)$ and power balance constraint $F_{p b c}\left(P g_{i}\right)$ as in (2).

$$
f i t=\frac{1}{F_{\cos t}+F_{p b c}}
$$

where;

$$
\begin{aligned}
& F_{\cos t}=1+a b s \frac{\left(\sum_{i=1}^{n} F_{i}\left(P g_{i}\right)-F_{\min }\right)}{\left(F_{\max }-F_{\min }\right)} \\
& F_{p b c}=1+\left(\sum_{i=1}^{n} P g_{i}-P_{D}-P_{l o s s}\right)^{2}
\end{aligned}
$$

$F_{\max }$ maximum generation cost among all individuals in the initial population;

$F_{\min }$ minimum generation cost among all individuals in the initial population.

Step4: the best value among all the pbest values (gbest) is identified.

Step5: new velocities for the particles are calculated using (7). The new velocity is simply the old velocity scaled by $\omega$ and increased in the direction of gbest and pbest for that particle dimension.
In this paper, the weighting factor and the two learning factors are dynamically tuned using fuzzy rules.

Step6: the positions for each particle are updated using (8). The resulting position of a particle is not always guaranteed to satisfy the inequality constraints.

If $v_{i, j}>V_{j}^{\max }$, then $v_{i, j}=V_{j}^{\max }$;

If $v_{i, j}<V_{j}^{\min }$, then $v_{i, j}=V_{j}^{\min }$.

Stap7: New objective function values are calculated for the new positions of the particles. If the new value is better than the previous pbest, the new value is set to pbest. If the stopping criterion is met, the positions of particles represent the optimal solution; otherwise the procedure is repeated from step4.

\section{DECOMPOSED NETWORK STRATEGY}

\section{Initialization based in Decomposition Procedure}

The main idea of the proposed approach is to optimize the active power demand for each partitioned network to minimize the total fuel cost. An initial candidate solution generated for the global $\mathrm{N}$ population size.

- For each decomposition level estimate the initial active power demand:

For $\mathrm{NP}=2 \quad$ Do

$$
\begin{aligned}
P d 1 & =\sum_{i=1}^{M 1} P_{G i} \\
P d 2 & =\sum_{i=1}^{M 2} P_{G i}=P D-P d 1
\end{aligned}
$$
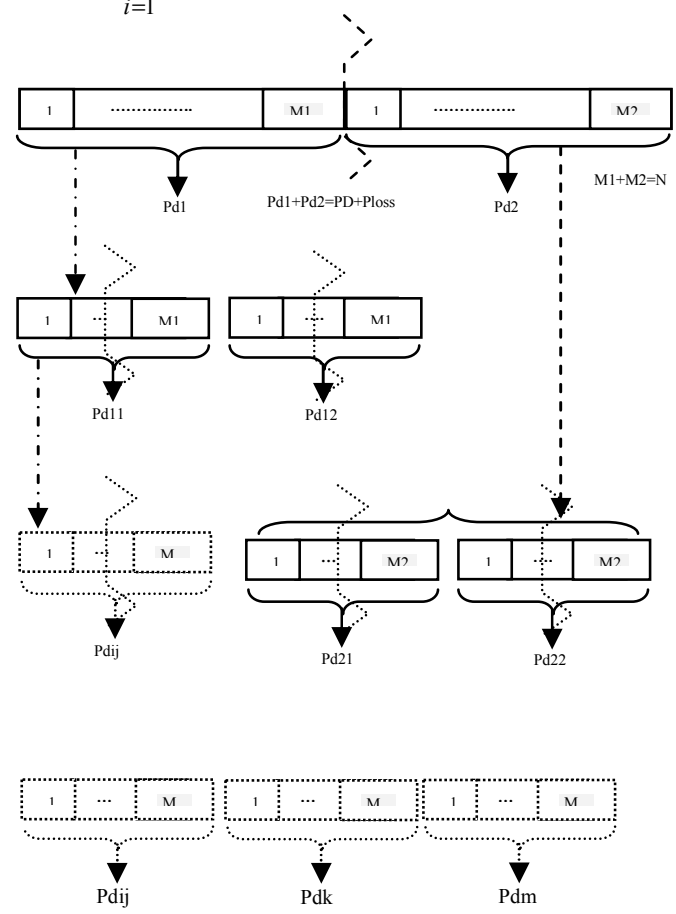

Fig. 5 Mechanism of search partitioning 
Where NP the number of partition;

$P d 1$ : the active power demand for the first initial partition.

$P d 2$ : the active power demand for the second initial partition.

$P D$ : the total active power demand for the original network.

The following equilibrium equation should be verified for each decomposed level:

For level 1:

$$
P d 1+P d 2=P D+\text { Ploss }
$$

\section{Final Search Mechanism}

- All the sub-systems are collected to form the original network, global data base generated based on the best results $U_{\text {best }}^{\text {Parti }}$ of partition 'i' found from all sub-populations.

\section{- Migration Procedure}

The migration operation is newly introduced in the parallel PSO mechanism, thereby can effectively explore and exploit promising regions in a search space. This new mechanism based migration between individuals from different subsystems makes the swarm to react more by changing experiences.

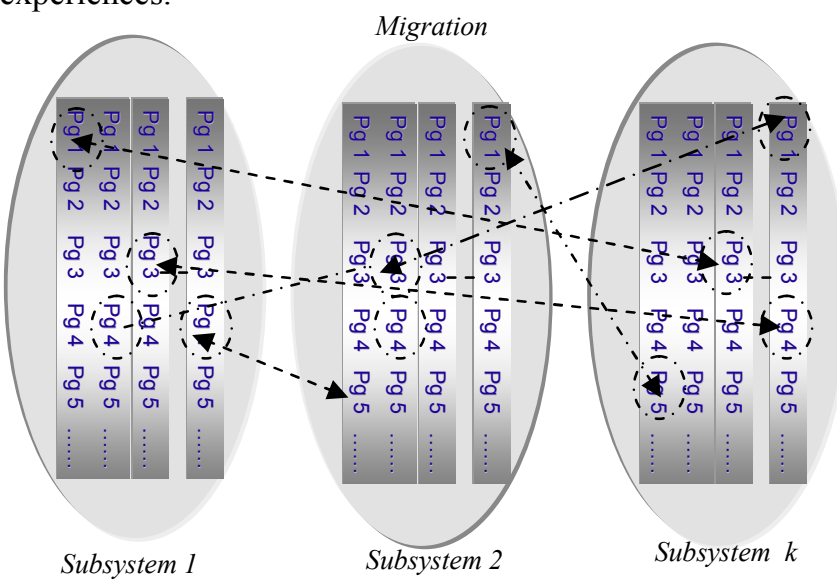

Fig 6 Illustration of the migration operation.

Fig 6 shows the mechanism of migration operation between individual from different subsystems.

\section{-Choose arbitrary two subsystems}

-Choose arbitrary two individuals from these subsystems

-Make migration.

-Evaluate fitness function with these new individuals

- Save the best cost

$-\ldots$.

- The final solution $U_{\text {best }}^{\text {Global }}$ is found out after reactive power planning procedure to adjust the reactive power generation limits, and voltage deviation, the final optimal cost is modified to compensate the reactive constraints violations. Fig 7 illustrates the basic steps of the proposed approach.

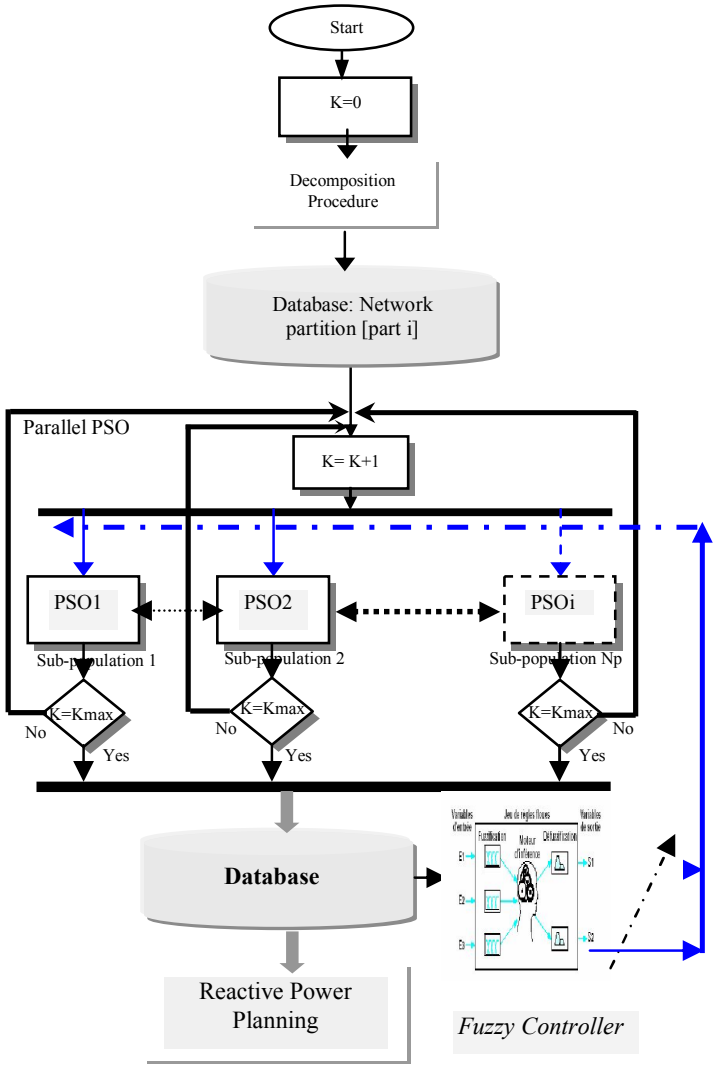

Fig 7 Procedure of parallel swarm optimization approach for EPD.

\section{V.APPLICATION STUDY}

The proposed algorithm is developed in the Matlab programming language using 6.5 version. The proposed approach has been tested on a large electrical network test 40 generating units with consideration of valve point effect.

\section{A. Test System 1}

In this application power system has 40 -generating units. Total load demand of the system is $10500 \mathrm{MW}$. This is a larger system, the number of local optima, complexity and nonlinearity to the solution procedure is enormously increased. The system data can be retrieved from [5]. The final fuel cost and output power for all generating units were summarized in Table I.

TABLE I

ECONOMIC DisPatCh RESULTS FOR 40-GENERATING Units using the PROPOSED APPROACH: PD $=10500 \mathrm{MW}$

\begin{tabular}{|c|c|c|c|c|c|c|c|}
\hline $\begin{array}{c}\text { Unit } \\
\mathrm{N}^{0}\end{array}$ & $\begin{array}{c}P_{\min } \\
(\mathrm{MW})\end{array}$ & $\begin{array}{c}P_{\max } \\
(\mathrm{MW})\end{array}$ & $\begin{array}{c}P g_{i} \\
(\mathrm{MW})\end{array}$ & $\begin{array}{c}\text { Unit } \\
\mathrm{N}^{\circ}\end{array}$ & $\begin{array}{c}P_{\min } \\
(\mathrm{MW})\end{array}$ & $\begin{array}{c}P_{\max } \\
(\mathrm{MW})\end{array}$ & $\begin{array}{c}P g_{i} \\
(\mathrm{MW})\end{array}$ \\
\hline 1 & 36 & 114 & 110.7957 & 21 & 254 & 550 & 523.2753 \\
\hline 2 & 36 & 114 & 110.8120 & 22 & 254 & 550 & 523.2753 \\
\hline 3 & 60 & 120 & 97.3958 & 23 & 254 & 550 & 523.2770 \\
\hline
\end{tabular}




\begin{tabular}{|c|c|c|c|c|c|c|c|}
\hline $\begin{array}{l}\text { Unit } \\
\mathrm{N}^{\circ}\end{array}$ & $\begin{array}{c}P_{\min } \\
(\mathrm{MW})\end{array}$ & $\begin{array}{l}P_{\max } \\
(\mathrm{MW})\end{array}$ & $\begin{array}{l}P g_{i} \\
(\mathrm{MW})\end{array}$ & $\begin{array}{l}\text { Unit } \\
\mathrm{N}^{\circ}\end{array}$ & $P_{\text {min }}$ & $\begin{array}{l}P_{\max } \\
(\mathrm{MW})\end{array}$ & $\begin{array}{l}P g_{i} \\
(\mathrm{MW})\end{array}$ \\
\hline 4 & 80 & 190 & 179.7290 & 24 & 254 & 550 & 523.2753 \\
\hline 5 & 47 & 97 & 87.7917 & 25 & 254 & 550 & 523.2915 \\
\hline 6 & 68 & 140 & 139.9959 & 26 & 254 & 550 & 523.2915 \\
\hline 7 & 110 & 300 & 259.5956 & 27 & 10 & 150 & 10.0000 \\
\hline 8 & 135 & 300 & 284.5956 & 28 & 10 & 150 & 10.0000 \\
\hline 9 & 135 & 300 & 284.5956 & 29 & 10 & 150 & 10.0000 \\
\hline 10 & 130 & 300 & 130.0000 & 30 & 47 & 97 & 87.8121 \\
\hline 11 & 94 & 375 & 94.0000 & 31 & 60 & 190 & 189.9959 \\
\hline 12 & 94 & 375 & 94.0121 & 32 & 60 & 190 & 190.0000 \\
\hline 13 & 125 & 500 & 214.7557 & 33 & 60 & 190 & 190.0000 \\
\hline 14 & 125 & 500 & 394.2753 & 34 & 90 & 200 & 164.7957 \\
\hline 15 & 125 & 500 & 394.2753 & 35 & 90 & 200 & 194.4056 \\
\hline 16 & 125 & 500 & 394.2753 & 36 & 90 & 200 & 200.0000 \\
\hline 17 & 220 & 500 & 489.2753 & 37 & 25 & 110 & 110.0000 \\
\hline 18 & 220 & 500 & 489.2753 & 38 & 25 & 110 & 109.9959 \\
\hline 19 & 242 & 550 & 511.2915 & 39 & 25 & 110 & 110.0000 \\
\hline 20 & 242 & 550 & 511.2753 & 40 & 242 & 550 & 511.2915 \\
\hline & \multicolumn{6}{|c|}{ Total power output (MW) } & 10,500 \\
\hline & \multicolumn{6}{|c|}{ Total generation cost $(\$ / \mathrm{h})$} & 121414.18337 \\
\hline
\end{tabular}

\section{DISCUSSIONS}

\section{A. Solution Quality}

Observing the comparison results depicted in Table II, the proposed hybrid approach is shown to be more efficient than the other global optimization methods. Details results will be given in the next full paper.

\section{B. Computational Efficiency}

Computational efficiency analysis is an important index to test and validate the robustness of an algorithm. The mean CPU time to converge to the best solution have been observed and shown in Table II. The proposed approach takes an average CPU time of $8.54 \mathrm{~s}$ to find the best near global solution. Fig 8 shows clearly the performance of the convergence characteristic curve of the fuzzy controlled PSO based decomposed procedure for one partition.

TABLE II

COMPARISON OF EPGA WITH OTHER GLOBAL OPTIMIZATION METHODS 40-GENERATING UNITS PD $=10500 \mathrm{MW}$

\begin{tabular}{c|cc}
\hline Methods & Minimum Cost(\$/h) & Average CPU time (s) \\
ICA-PSO [2] $^{*}$ & 121413.200 & 139.9200 \\
SA-PSO [2] & 121430.000 & - \\
\hline
\end{tabular}
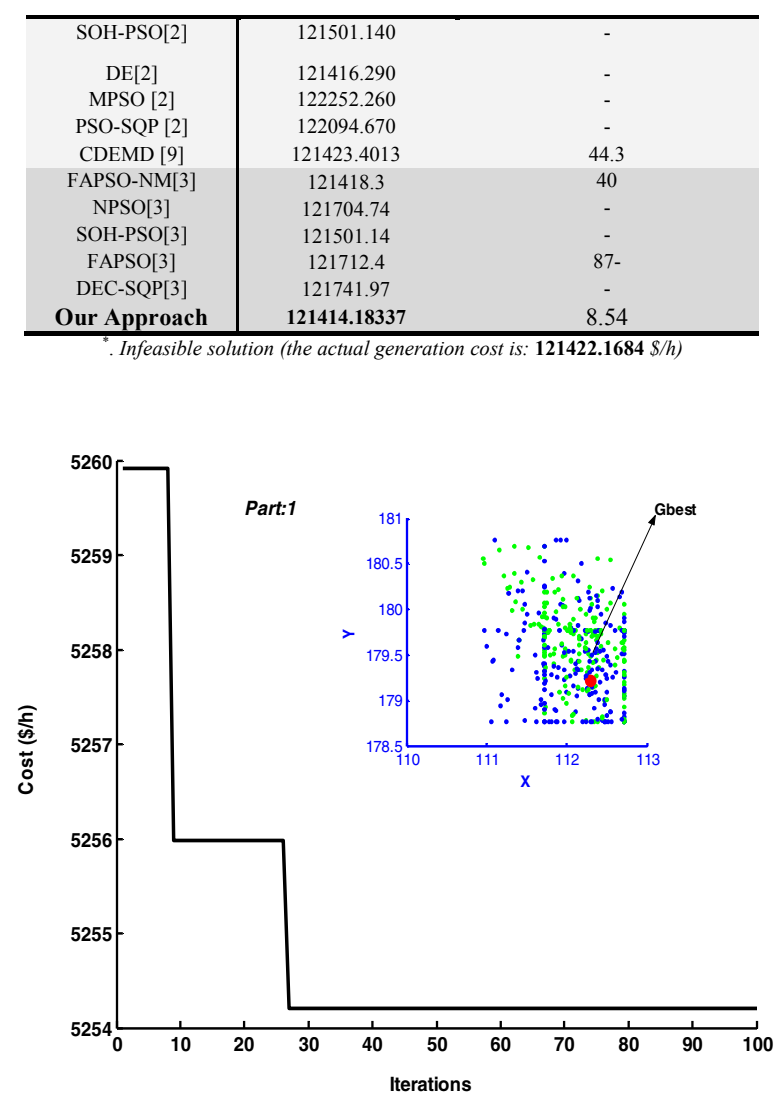

Fig 8 Convergence characteristic of 40 -generator system (with valve point loading) for the first partition-Part1 (4 generating units).

\section{CONCLUSION}

Application of an improved fuzzy controlled parallel PSO based decomposed network to enhance the economic dispatch for large power system with consideration of non-smooth fuel cost functions is demonstrated in this paper. In the first stage a practical rules formulated within fuzzy rules strategy designed to adjust dynamically three PSO parameters. In the second stage a decomposition mechanism is proposed to search the efficient partitioned networks to adjust the first solution found. A parallel execution of the adapted PSO associated to each decomposed search space.

The performance of the proposed approach was tested with large test system (40-generating units) with consideration of valve point effect, the results of the proposed algorithm compared with recent global optimization methods. It is observed that the proposed approach is capable of finding the near global solution of non-linear and non-differentiable objective functions and obtain a competitive solution at a reduced time.

\section{REFERENCES}

[1] R. C. Bansal, "Otimization methods for electric power systems: an overview," International Journal of Emerging Electric Power Systems, vol. 2, no. 1, pp. 1-23, 2005. 
[2] J. G. Vlachogiannis, and K. Y. Lee, "Economic dispatch-A comparative study on heuristic optimization techniques with an improved coordinated aggregation-based PSO," IEEE Trans. Power Systems, vol. 24, no. 2, pp. 991-10001, 2009.

[3] Taher Nikman, "A new fuzzy adaptive hybrid particle swarm optimization algorithm for non-linear, non-smooth and non-convex economic dispatch," Journal of Applied Energy, Vol. 87, pp. 327-339, 2010.

[4] C. Chien Kuo, "A novel string structure for economic dispatch problems with practical constraints," Journal of Energy Conversion and management, Elsevier,vol. 49, pp. 3571-3577, 2008.

[5] S. Pothiya, I. Nagamroo, and W. Kongprawechnon, "Application of mulyiple tabu search algorithm to solve dynamic economic dispatch considering generator constraints," Journal of Energy Conversion and management, Elsevier, vol. 49, pp. 506-516, 2008.

[6] B. Mahdad, T. Bouktir, K. Srairi, "OPF with Environmental Constraints with SVC Controller using Decomposed Parallel GA: Application to the Algerian Network" Journal of Electrical Engineering \& Technology, Korea, Vol. 4, No.1, pp. 55 65, March 2009.

[7] K. T. Chaturvedi, M. Pandit, and L. Srivastava, "Self-organizing hierarchical particle swarm optimization for nonconvex economic dispatch," IEEE Trans. Power Syst., vol. 23, no. 3, pp. 1079-1087, Aug. 2008.

[8] B. K. Panigrahi, V. R. Pandi, and S. Das, "Adaptive particle swarm optimization approach for static and dynamic economic load dispatch," Energy Convers. Manage., vol. 49, no. 6, pp. 1407-1415, 2008.

[9] L. D. S. Coelho and C.-S. Lee, "Solving economic load dispatch problems in power systems using chaotic and Gaussian particle swarm optimization approaches," Int. J. Elect. Power Energy Syst., vol. 30, no. 4, pp. 297-307, 2008.

[10] A. I. Selvakumar and K. Thanushkodi, "A new particle swarm optimization solution to nonconvex economic dispatch problems," IEEE Trans. Power Syst., vol. 22, no. 1, pp. 42-51, Feb. 2007.

[11] J.-B. Park, K.-S. Lee, J.-R. Shin, and K. Y. Lee, "A particle swarm optimization for economic dispatch with nonsmooth cost functions," IEEE Trans. Power Syst., vol. 20, no. 1, pp. 34-42, Feb. 2005.

[12] T. Aruldoss, A. Victoire, and A. E. Jeyakumar, "Hybrid PSO-SQP for economic dispatch with valve-point effect," Elect. Power Syst. Res., vol. 71, no. 1, pp. 51-59, 2004.

[13] C. C. Kuo, "A novel coding scheme for practical economic dispatch by modified particle swarm approach," IEEE Trans. Power Syst., vol. 23, no. 4, pp. 1825-1835, Nov. 2008.

[14] L. D. S. Coelho and V. C. Mariani, "Particle swarm approach based on quantum mechanics and harmonic oscillator potential well for economic load dispatch with valve-point effects," Energy Convers. Manage., vol. 49, no. 11 , pp. 3080-3085, 2008.

[15] T. A. A. Victoire and A. E. Jeyakumar, "Hybrid PSO-SQP for economic dispatch with valve-point effect," Elect. Power Syst. Res., vol. 71, pp. 51-59, Sep. 2004.

[16] Belkacem Mahdad, T. Bouktir, K. Srairi, and M. EL. Benbouzid, "Dynamic strategy based fast decomposed GA coordinated with FACTS devices to enhance the optimal power flow," Accepted at Journal of Energy Conversion and Management(IJECM), Elsevier December 2009.

[17] Belkacem Mahdad, T. Bouktir, K. Srairi, and M. EL. Benbouzid "Optimal Power Flow with Discontinous Fuel Cost Functions Using Decomposed GA Coordinated with Shunt FACTS," Journal of Electrical Engineering \& Technology, Korea, Vol. 4, No. 4, pp. 315 322, December 2009.

[18] M. Fesanghary, and M. M. Ardehali, "A novel meta-heuristic optimization methodology for solving various types of economic dispatch problem," Journal of Energy, Elsevier, vol. 34, pp. 757-766, 2009.

[19] L. S. Coelho, R. C. Thom Souza, and V. Cocco mariani, "Improved differential evoluation approach based on clutural algorithm and diversity measure applied to solve economic load dispatch problems," Journal of Mathemtics and Computers in Simulation, Elsevier, 2009.

[20] B. Mahdad, T. Bouktir, K. Srairi, "Optimal power flow for large-scale power system with shunt FACTS using fast parallel GA,". The 14th IEEE Mediterranean on Electrotechnical Conference, 2008. MELECON 5-7 May 2008. pp. 669-676.
[21] R. C. Eberhart and Y. Shi, "Particle swarm optimization: developments, applications and ressources," in Proc.2001 Congr. Evolutionary Computation, vol. 1, 2001.

[22] Belkacem Mahdad, Optimal Power Flow with Consideration of FACTS devices Using Genetic Algorithm: Application to the Algerian Network, Doctorat Thesis, Biskra University Algeria, 2010. 